FACULDADE DE CIÊNCIAS ECONÔMICAS DA UFRGS
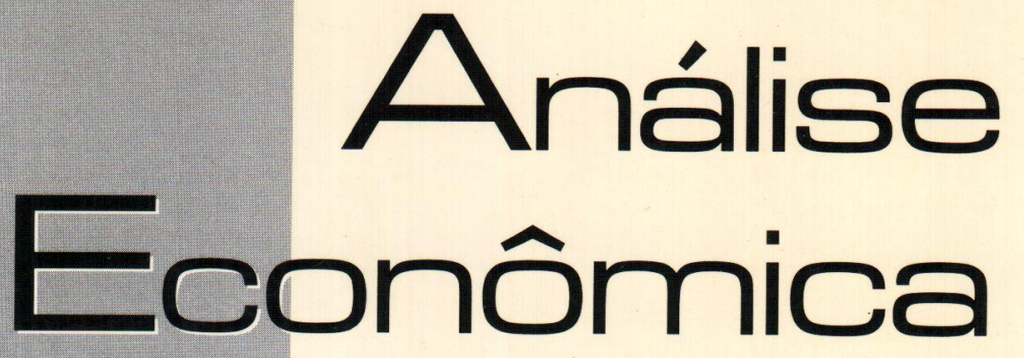

A CIÉNCIA ECONOMICA NA EUROPA E NOS Estados Unidos: PluRAlismo Versus MONISMO

ANTONio Maria da SiLveira

A EXPANSÃO DO COMERCIO MUNDIAL: IMPLICACOO ES SOBRE A HIPÓ TESE DE CONVERGENCIA

MANOEL BOSCO DE ALMEIDA

O SETOR AGRICOLA NA ÁREA DE LIVRE COMERCIO DAS AMÉRICAS: DESAFIOS DA INTEGRAÇÃO REGIONAL

PAULO D. WAQUIL.

PEQUENOS E MEDIOS FABRICANTES DE BENS DE CAPITAL FRENTE AS MUDANÇAS NA ECONOMIA BRASILEIRA

HOYEDO NUNES LINS

RISCOS NA ATIVIDADE BANCÁRIA EM CONTEXTO DE ESTABILIDADE DE PREÇOSE DE ALTA INFLAÇÃO

LUIS FERNANDO RODRIGUES DE Paula

O FIO DA NAVALHA DE HARROd EA RESPOSTA DA ESCOLA DE CAMBRIDGE MARIo AUGusto Bertella

A DINAMMICA FINANCEIRA INTERNACIONAL E A TENDENCIA Ã DOLARIZAÇÄO DAS ECONOMIAS LATINO-AMERICANAS

MARCOS ANTONIO MACEDO CinTRA

TEMPORALIDADE DA RIQUEZA - TEORIA DA DINAMMICA E FINANCEIRIZAÇÃO DO CAPITALISMO - RESENHA

Gentil Corazza

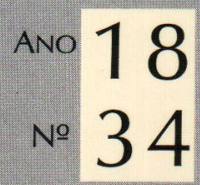


Universtode Federal do Rio Grande do Sul

Reitora: Prof ${ }^{a}$. Wrana Maria Panizzi

Faculdade de Crências Econômicas.

Diretora: Prof ${ }^{4}$. Otilia Beatriz Kroeff Carrion

Centro de Estudos e Pesquisas Econômicas

Diretor: Prof. Fernando Ferrari Filho

Departamento de Ciências Económicas

Chefe: Prof. Luiz Alberto Oliveira Ribeiro de Miranda

Departamento de Crências Contábeis e Atuariais

Chefe: Prof. João Marcos Leão da Rocha

Curso de Pós-Graduação em Economia

Coordenador: Prof Marcelo Savino Portugal

Curso de Pós-Graduação em Desenvolvimento Rurai

Coordenador: Prof Carlos Guilherme A. Mielitz Netto

Consel.ho Eomorial: Achyles B. Costa, Aray M. Feldens, Carlos A Crusius, Carlos G. A Mielitz Netto, Eduardo A. Maldonado Filho, Eduardo P. Ribeiro, Eugênio Lagemann, Fernando Ferrari Filho, Gentil Corazza, Jan A. Kregel, Marcelo S. Portugal, Nali J. Souza, Otília B. K Carrion, Paulo A. Spohr, Paulo D. Waquil, Pedro C. D. Fonseca, Philip Arestis, Roberto C. Moraes, Ronald Otto Hillbrecht, Stefano Florissi, Eleutério F. S. Prado (USP), Fernando H Barbosa (FGV/RJ), Gustavo Franco (PUC/RJ), João R. Sanson (UFSC), Joaquim P. Andrade (UnB), Juan H. Moldau (USP), Paul Davidson (Univ of Tennessee), Werner Baer (Univ. of Mlinois)

Comissāo Eoitonial: Eduardo Augusto Maldonado Filho, Fernando Ferrari Filho, Gentil Corazza, Marcelo Savino Portugal, Paulo Dabdab Waquil, Roberto Camps Moraes.

EdITor: Gentil Corazza

EdrTor Adjunto: Pedro Silveira Bandeira

Secretarus: Márcio Souza de Vargas

REVISĩo de teXtos: Vanete Ricacheski

Fundador: Prof. Antônio Carlos Santos Rosa

Os materiais publicados na revista Análise Econômica são da exclusiva responsabilidade dos autores. É permitida a reprodução total ou parcial dos trabalhos, desde que seja citada a fonte. Aceita-se permuta com revistas congêneres. Aceitam-se, também, livros para divulgação, elaboração de resenhas e recensões. Toda correspondência, material para publicação (vide normas na terceira capa), assinaturas e permutas devem ser dirigidos ao seguinte destinatário:

Prof. Genth Corazza

Revisia Anáxise Econômica - Av. João Pessoa, 52 CEP 90040-000 PORTO ALEGRE - RS, BRASIL

Telefones: (051) 316-3513 316-3440 - Fax: (051) 316-3990 rae@vortex.ufrgs.br

Análise Econômica

Ano $18, n^{\circ} 34$, setembro, 2000 - Porto Alegre

Faculdade de Ciências Econômicas, UFRGS, 2000

Periodicidade semestral, março e setembro

1. Teoria Econômica - Desenvolvimento Regional Economia Agrícola - Pesquisa Teórica e Aplicada -

Periódicos. I Brasil

Faculdade de Ciências Econômicas,

Universidade Federal do Rio Grande do Sul.

CDD 330.05

CDU $33(81)(05)$ 


\title{
Pequenos e médios fabricantes de bens de capital frente às mudanças na economia brasileira'
}

\author{
Hoyêdo Nunes Lins ${ }^{2}$
}

\begin{abstract}
Resumo: A economia brasileira foi consideravelmente afetada pela abertura comercial dos anos 90. A indústria foi afetada de modo particular, pois já se encontrava debilitada devido às crises da década anterior. Este artigo aborda os efeitos da abertura em 20 pequenas e médias empresas (PMEs) de bens de capital localizadas em Santa Catarina. Baseado em pesquisa de campo, realizada por meio de entrevistas, e levando em conta o debate sobre diferenças entre firmas, o estudo foca as situações competitivas das PMEs, considerando estas posições em relação às trajetórias individuais das últimas. Sublinha-se que as relações envolvendo mudanças econômicas gerais, condutas empresariais e competitividade são bastante complexas.
\end{abstract}

Palavras-chave: Abertura comercial, PMEs de bens de capital, competitividade.

Abstract: The Brazilian economy was deeply affected by trade opening in the 90's. The manufacturing sector was particularly affected, since it was already debilitated by the crisis of the preceding decade. This article approaches the corresponding effects on 20 small and medium sized enterprises (SMEs) producing capital goods in Santa Catarina. Based on field research carried on through interviews, and drawing on the debate about firm differences, the study focuses the SME's competitive situations in relation with the individual trajectories of the enterprises. It is argued that the relationships involving broad economic changes, the behaviour of the firms and competitiveness are quite complex.

Key-words: Trade opening, SMEs of capital goods, competitiveness.

\section{Introdução}

O complexo metal-mecânico brasileiro foi severamente afetado pelas mudanças macroeconômicas dos anos 90, principalmente pela abertura comercial, e, a exemplo de outros setores, procurou se reestruturar ${ }^{3}$. Isso implicou, sobretudo, empresas maiores. Sobre as pequenas e médias empresas

\footnotetext{
${ }^{1}$ Versão modificada do trabalho apresentado no XXV Encontro Nacional de Economia da ANPEC, realizado em Recife entre 10 e 12 de dezembro de 1997, intitulado "Abertura comercial e competitividade de pequenos e médios fabricantes de bens de capital". Cf' Lins (1997)

${ }^{2}$ Professor Doutor, Titular, do Depto de Ciências Econômicas e do Programa de Pós-Graduação em Economia da Universidade Federal de Santa Catarina.

${ }^{3}$ Sobre a reestruturação industrial no Brasil diante das mudanças econômicas recentes, consultar, por exemplo, Bielschowsky e Stumpo (1996) e Miranda (1996).
} 
(PMEs), sabe-se menos, aparentemente. Porém, o modo como estas são atingidas pelas mudanças macroeconômicas é tema de interesse, seja pelo papel de tais firmas nos mercados industriais (Audretsch, 1994) e na geração de empregos (Sengenberger, 1988), seja pela sua vulnerabilidade estrutural.

Este trabalho investiga os efeitos da abertura comercial em PMEs fabricantes de bens de capital situadas em Santa Catarina. O tema geral é o das inter-relações entre os níveis micro e macroeconômico, explorado a partir de entrevistas com 20 produtores de máquinas e equipamentos para uso industrial de várias regiões do Estado.

\section{Competitividade das PMEs e seus fatores}

Quase metade das empresas estudadas acusou efeitos do aumento das importações, mas só três assinalaram pressões com intensidade capaz de provocar considerável redução nos preços praticados. Isso derivava de vantagens ligadas a preços, possibilidades de prestação de serviços pós-venda e especificações técnicas dos produtos. Mesmo assim, sete firmas reconheceram desvantagens em tecnologia. Para algumas, preço, qualidade e as condições para compra oferecidas por fabricantes estrangeiros figuravam entre as dificuldades para concorrer (Quadro 1).

Quadro 1: Concorrência de produtos importados

\begin{tabular}{|c|c|}
\hline Indicadores & Número de firmas \\
\hline $\begin{array}{l}\text { Impacto da abertura comercial } \\
\text { Não tem afetado } \\
\text { Tem afełado, mas pouco } \\
\text { Tem afetado muito }\end{array}$ & $\begin{array}{l}12 \\
5 \\
3 \\
\end{array}$ \\
\hline $\begin{array}{l}\text { Desvantagens declaradas frente d́s importações lal } \\
\text { Preço } \\
\text { Qualidade } \\
\text { Tecnologia } \\
\text { Condições de financiamento } \\
\text { Nerhuma }\end{array}$ & $\begin{array}{c}3 \\
3 \\
7 \\
3 \\
10\end{array}$ \\
\hline $\begin{array}{l}\text { Vantagens declaradas frente ós imporiações (a) } \\
\text { Preço } \\
\text { Serviços pós-venda } \\
\text { Especificações técnicas/tecnologia apropriada } \\
\text { Outras } \\
\text { Nenhuma }\end{array}$ & $\begin{array}{l}14 \\
8 \\
8 \\
2 \\
3 \\
\end{array}$ \\
\hline
\end{tabular}

Fonte: Pesquisa direta nas empresas.

(a) O numero de indicações supera o número de firmas porque muitas assinalaram vários tipos de vantagens e desvantagens. 
Algumas firmas podem ter superestimado a própria capacidade competitiva, mas a incidência de aspectos como segmentação de mercado e produção sob encomenda (para a maioria, as vendas a pedido representavam todo o faturamento) ajuda a explicar as situações observadas. De outra parte, mais da metade exportava ou tinha exportado recentemente, geralmente para países latino-americanos, com base em vantagens de preço, qualidade e flexibilidade. Para a maior parte, as exportações não representavam muito: em nenhum caso superaram $35 \%$ das vendas e para a maioria não ultrapassavam $15 \%$.

A competitividade apresentada pelo coletivo de PMEs escorava-se em diferentes tipos de fatores.

\subsection{Organização produtiva, investimentos e capacitação tecnológica}

A maioria das firmas possuía escala de produção pelo menos similar à média nacional. Poucas operavam como subcontratadas, sem que tal condição representasse muito nas suas atividades. Inversamente, quase todas subcontratavam, mas isto raramente excedia a $20 \%$ da produção. Em relação aos investimentos, a situação era bastante heterogênea, mas para o maior número o coeficiente de investimento ${ }^{4}$ não era maior que $20 \%$, coerente com a necessidade, em 2/3 das PMEs, de renovação de mais de 1/5 do maquinário, e só metade incorporara equipamentos programáveis (em todos os casos, tornos $\mathrm{CNC}^{5}$ ).

As atividades de pesquisa e desenvolvimento $(\mathrm{P} \& D)$ foram robustecidas. A maioria das empresas dispunha de P\&D desde a década de 80 , mas os serviços de engenharia foram intensificados nos anos 90 . Todas possuíam engenheiros e técnicos, contingente que, em quase metade das firmas, superava $10 \%$ dos funcionários. Porém, a maior parte ampliou o respectivo grupo, cuja percentagem mais que dobrou em oito casos; ao mesmo tempo, cresceu o pessoal em atividades de projeto e desenvolvimento de produtos (Quadro 2).

\subsection{Aspectos gerenciais e iniciativas em qualidade e produtividade}

Os staffs dirigentes de mais da metade das PMEs conservavam sócios fundadores que, na maioria, atuavam auxiliados por profissionais. Também majoritárias eram as firmas que possuíam gerências, seja familiares, profissionais ou mistas. Metade não fazia estimativas de vendas, certamente pela elevada incidência de produção sob encomenda, e quando isso ocorria a atribuição era geralmente só dos sócios, como em outras questões administrativas.

\footnotetext{
${ }^{4}$ Considerou-se como coeficiente de investimento a razão entre o investimento acumulado no período 1988-1994 e o faturamento de 1994

${ }^{5}$ Controle Numérico Computadorizado
} 
Algumas empresas avançaram em qualidade e produtividade (Q\&P), às vezes com apoio externo. Contudo, pouco se fez sobre ISO 9000 e inovações organizacionais. Quando houve tais inovações, predominaram iniciativas envolvendo supervisão, just-in-time/kanban, administração participativa, reorganização de postos de trabalho, controle estatístico de processos e, principalmente devido à modernização do maquinário, racionalização de pessoal (Quadro 3).

Quadro 2: Investimentos, tecnologia e capacitação tecnológica

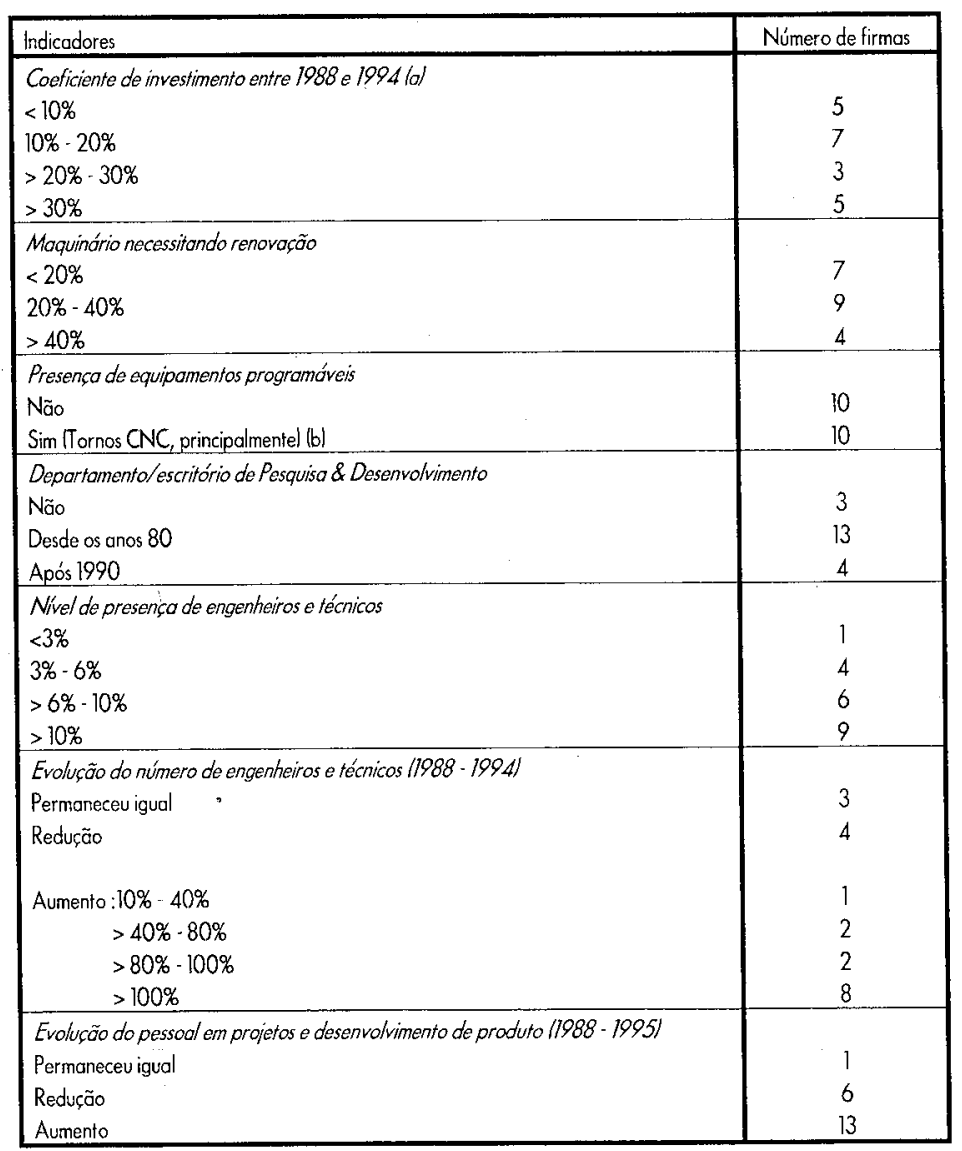

Fonte: Pesquisa direta nas empresas.

(a) Coeficiente de investimento: razão entre os investimentos realizados no período 1988 -1994 e o faturamento de 1994

(b) CNC significa Controle Numérico Computadorizado. 
Quadro 3: Iniciativas relacionadas a qualidade e produtividade

\begin{tabular}{|l|c|}
\hline Indicadores & Número de firmas \\
\hline Programas de qualidade e produtividade & 7 \\
Não & 7 \\
Sim & 6 \\
\hline Iniciativas par ciais & \\
\hline Mudanças organizacionais e/ou novos procedimentos & 12 \\
Não & \\
& 4 \\
Novas formas de supervisão & 4 \\
Just-in-time/kanban & 4 \\
Administração participativa & 3 \\
Reorganização de postos de trabalho & 3 \\
Controle estatístico de processos & 3 \\
Racionalização do pessoal & 2 \\
Células de manufaturo & 2 \\
Círculos de controle de qualidade & 1 \\
Novas gerências & \\
\hline Atitude frente ḋs normas da /SO 9000 & 11 \\
Não implantou & 5 \\
Não implantou, mas interessado & 4 \\
\hline Implantou/em implantação & \\
\hline
\end{tabular}

Fonte: Pesquisa direta nas empresas

A pesquisa mostrou que as firmas diferenciavam-se em relação às consequiências da abertura comercial, ao desempenho exportador e aos fatores de competitividade, suscitando a seguinte indagação. Que relações podem existir entre as situações competitivas exibidas e os níveis de presença de tais fatores?

\section{Competitividade versusfatores de competitividade: diferenciação interfirma}

A questão que encerra a parte anterior só pode ser abordada através da observação individual das empresas. $O$ assunto é o das diferenças entre firmas, objeto de desenvolvimento teórico recente que vale a pena referir. 


\subsection{O problema das diferenças entre empresas}

O referido tema tem sido focalizado nas abordagens neo-schumpeterianas sobre dinâmica econômica, como na análise sobre paradigmas e trajetórias tecnológicas ${ }^{6} \mathrm{e}$, sobretudo, na tradição evolucionista, que parece oferecer o melhor tratamento da questão. De fato, em artigo do começo dos anos 90, Nelson (1991) salienta as limitações da economia neoclássica sobre a matéria, discute alguns trabalhos correspondentes e apresenta os termos de um enfoque próprio. A passagem abaixo resume parte importante da visão do autor.

Uma premissa básica da teoria evolucionária é que o mundo é complicado demais para que uma firma o compreenda totalmente, no sentido em que uma firma entende seu mundo na teoria neoclássica. Há certas características da estratégia de uma firma, e de sua associada estrutura, em relação às quais o management pode ter confiança de que ampliarão as chances para o desenvolvimento das capacidades que a firma necessita para ser bem-sucedida. Existem outras características que parecem uma prescrição ao insucesso. Entretanto, há muito espaço intermediário, no qual a firma (ou o seu management) simplesmente tem que depositar suas apostas, consciente de que não sabe no que resultarão.

Assim, diversidade de firmas é exatamente o que alguém esperaria no âmbito da teoria evolucionária. É virtualmente inevitável que as empresas escolham estratégias de algum modo diferentes. Estas, por seu turno, farão com que as firmas tenham estruturas e capacidades centrais (core capabilities) diferentes, incluindo suas capacidades em $P \& D$. As firmas inevitavelmente seguirão trajetórias (paths) de algum modo diferentes. Algumas se revelarão lucrativas, tendo em vista o que outras firmas estão fazendo e o modo como os mercados evoluem, outras não (Nelson, 1991, p.69).

Assim, há espaços discricionais em nível de firma que resultam em diferentes respostas aos processos mais gerais, sendo as possibilidades presentes e futuras decisivamente influenciadas por opções, estratégias e desempenhos do passado. Ou seja, firmas integrantes dos mesmos contextos e afetadas pelas mesmas condições gerais podem exibir comportamentos distintos e trilhar caminhos diferentes. Cabe assinalar que empresas com trajetórias pouco brilhantes e condutas não propriamente estratégicas diante de mudanças no ambiente competitivo podem conservar, ainda assim, parte de seus espaços de atuação. O motivo é que a situação de uma firma é influenciada por múltiplos fatores, um aspecto que tem especial relevância quando se trata de PMEs: à variedade de elementos que intervêm no comportamento em nível microeconômico, acrescenta-se a heterogeneidade típica desse universo empresarial, onde quaisquer transformações macroeconômicas tendem a produzir efeitos bastante diversificados?

Consultar Dosi (1988), por exemplo.

${ }^{7}$ Cf. Yoguel (1996). 
Num estudo empírico, só mediante análise individual torna-se possível lançar alguma luz sobre a multiplicidade de formas pelas quais as PMEs absorvem as transformações mais gerais e reagem a elas.

\subsection{Diferenciação das firmas do painel}

Focaliza-se a seguir a situação de cada firma do painel estudado. As PMEs aparecem agrupadas conforme os seus principais tipos de produtos.

3.2.1 Fabricantes de maquinário para o setor têxtil

A pressão da concorrência externa foi assinalada por três desses fabricantes, mas revelou-se intensa só em dois casos: uma pequena empresa de Joinville (região norte) e uma média empresa de Blumenau (Vale do Itajaí), ambas sem atividade exportadora.

O primeira firma investira, mas sem adquirir equipamentos programáveis ou incorporar dispositivos microeletrônicos aos produtos. Introduzira $\mathrm{P} \& \mathrm{D}$, incrementara a proporção de engenheiros e técnicos e do pessoal em projetos e desenvolvimento de produtos e, embora sem mudanças organizacionais, avançara em Q\&P. Interagia razoavelmente na região, inclusive terceirizando o correspondente à metade do valor produzido. Sem vínculos internacionais, e sem ter ampliado o uso de insumos importados (não ultrapassavam $4 \%$ do total), a empresa permanecia em nicho de produtos semi-automatizados, com linhas novas que não representavam mais de $15 \%$ do faturamento. As importações afetaram a firma porque seus produtos eram defasados, e as empresas têxteis nacionais passaram a importar máquinas mais sofisticadas a preços atraentes. No entanto, a firma não evidenciou estratégia clara frente ao problema.

Para a outra firma, foi a entrada de máquinas de costura de menor sofisticação, asiáticas, que se revelou dramática. A qualidade e a durabilidade desse maquinário tendem a ser menores, mas seus baixos preços faziam a diferença. Por outro lado, a maior capacidade tecnológica de concorrentes nacionais deslocou a empresa nos segmentos de maior sofisticação. A firma investira em aumento de capacidade e qualidade, introduzindo tornos CNC e setor de P\&D, instalando centro de usinagem, dobrando a participação de engenheiros e técnicos e elevando o contingente em atividades de projeto e desenvolvimento de produto. Avançou em Q\&P, inovações organizacionais e na ISO 9000, mas não interrompeu linhas de produtos ou incorporou novidades que representassem mais de $15 \%$ do faturamento, e não utilizava insumos importados e tampouco possuía vínculos no exterior. As interações locais eram precárias: a firma subcontratava menos de $5 \%$ do valor produzido, não participava de esquemas de cooperação e sequer tinha relações institucionais relevantes. Assim, embora acenasse com reestruturação, tinha horizonte competitivo opaco, de continuidade dos problemas. 
A outra empresa afetada era de tamanho médio, produzia em Joinville e tinha $15 \%$ das vendas relacionadas às exportações, configurando caso único de presença em mercados de países mais industriälizados, fruto de parceria com empresa alemã que incorporava componentes aos produtos e os distribuía na Europa Ocidental. Crescera nos anos 80 e investira razoavelmente desde 1990 , porém não possuía equipamento programável e necessitava renovar $1 / 5$ do maquinário, embora tivesse incorporado novas linhas de produtos, inclusive com dispositivos microeletrônicos, e fortalecido a $\mathrm{P} \& \mathrm{D}$. Conquanto dinâmica, a firma não registrava inovações organizacionais e ostentava iniciativas em Q\&P apenas parciais, além de precária inserção local: a cooperação era escassa, em que pese relações institucionais favoráveis. Os efeitos da abertura comercial refletiam um mix de produtos inferior ao dos concorrentes estrangeiros e a impossibilidade para acompanhar as condições de compra oferecidas por estes. As reações incluíram intensificação no ritmo de inovações, busca de parcerias internacionais e aumento no uso de componentes importados.

Duas firmas desse segmento, ambas exportadoras, declararam "imunidade" à abertura comercial.

Uma delas, de pequeno porte e localizada em Blumenau, investira em equipamento programável mas necessitava renovar $60 \%$ do maquinário. Dispunha de P\&D desde os anos 80 e ampliara o número de engenheiros e técnicos, porém perdera posição em termos de tecnologia e mercado. As novas linhas, que não abrangiam produtos com dispositivos microeletrônicos, só representavam $15 \%$ do faturamento. Nada realizara em Q\&P ou em inovações organizacionais, e a estrutura de gestão, muito centralizada, sequer apresentava gerências. Não utilizava insumos importados nem tinha acordos/parcerias no exterior, e sua inserção local era limitada: praticamente não subcontratava e tampouco mantinha relações cooperativas e institucionais. Fornecedora para segmento industrial pouco sofisticado, era firma diversificada e integrada, com perdas em economias de escala e especialização e com posição somente intermediária até no mercado regional. A "imunidade" frente às importações se explicava pelo segmento de mercado em que atuava. $O$ frete encarecia os produtos importados e os clientes preferiam prestação local de assistência técnica, mas essa "proteção" era eficaz porque o mercado da firma era pouco exigente, integrado sobretudo por pequenas e microempresas.

A outra empresa era também pequena e blumenauense, investira em equipamentos programáveis e possuía engenheiros e técnicos que representavam $11 \%$ do pessoal. As iniciativas em Q\&P foram parciais e desacompanhadas de inovações organizacionais. Apesar de dificuldades nos anos 80, apresentava grandes firmas têxteis como clientes e tinha posição de liderança no mercado brasileiro. Não utilizava insumos importados, mas as suas relações com o 
exterior, além de exportações para Argentina, Chile e Paraguai (que absorviam $7 \%$ das vendas), envolviam "ligações" tecnológicas com empresa alemã que resultaram em licença para fabricação. As relações locais tinham alguma importância, porém menos pela subcontratação do que pela parceria com grande empresa para desenvolvimento de produto. A "imunidade" frente às importações refletia o tipo de produto fabricado, mais simples e robusto, um aspecto potencializado pelo custo do frete dos importados, assinalado pela firma como proteção.

\subsubsection{Fabricantes de maquinário para a indústria cerâmica}

Metade desses fabricantes assinalou efeitos negativos da abertura comercial, como em uma média empresa de Criciúma (região sul) que nada investira em maquinário nem dispunha de equipamento programável, mas incorporara dispositivos microeletrônicos aos seus produtos. Possuía P\&D já nos anos 80 e avançou em Q\&P e inovações organizacionais, e seus engenheiros e técnicos, correspondentes a $17 \%$ do pessoal, mais que dobraram desde 1990 . Sem utilizar insumos importados ou exportar, subcontratava localmente $20 \%$ do que produzia, sem todavia assinalar qualquer vantagem locacional (como cooperação e vínculos institucionais) além da proximidade dos clientes ${ }^{8}$. A empresa reduzira o nível de atividade, e isso turvava ainda mais um cenário já dificultado pelas importações, cujo impacto derivava, basicamente, da incapacidade para acompanhar as condições de compra dos concorrentes externos.

Efeitos das importações foram também assinalados por uma média empresa de Criciúma que exportava ( $10 \%$ das vendas), investira em equipamento programável, avançara em Q\&P e protagonizara inovações organizacionais. Com P\&D desde os anos 80 , e engenheiros e técnicos que, embora em queda, representavam 7\% do pessoal, introduzira linhas (algumas registrando produtos com componentes microeletrônicos) que canalizavam todo o faturamento. Parcerias estrangeiras facilitavam o uso de insumos importados: a necessidade de materiais novos para a matrizaria impulsionou acordo com empresa italiana que incluía assistência técnica. As conseqüências negativas da abertura comercial resultaram da preferência dos grandes ceramistas por fornecedores estrangeiros, atualizados tecnologicamente. Contudo, o impacto foi pequeno, pois a empresa continuava a vender para PMEs de baixo dinamismo, consumidoras de produtos mais rudes e baratos.

As firmas não afetadas pela abertura comercial fabricavam máquinas e equipamentos para cerâmica vermelha.

Uma delas, de médio porte e instalada em Tubarão (Região Sul), exportava (30\% das vendas) para países latino-americanos e investira razoavelmente

\footnotetext{
${ }^{8}$ O sul catarinense é uma importante região ceramista: cerâmica branca, de revestimento.
} 
em maquinário. Possuía P\&D desde os anos 80, mas o aumento do número de engenheiros e técnicos só ocorreu posteriormente, desacompanhado de avanços em Q\&P e inovações organizacionais. As novas linhas não representavam mais de $10 \%$ do faturamento nem se caracterizavam pela incorporação de microeletrônica aos produtos. Acordos no exterior eram inexistentes e a interação local era precária, sem cooperação ou participação em associações empresariais. A conduta era claramente conservadora: não subcontratava porque o proprietário era contra. Mantinha-se em atividade, com poucos concorrentes nacionais e sem concorrência estrangeira, porque seu mercado era composto de pequenas e médias cerâmicas de reduzido dinamismo tecnológico, com necessidades restritas às máquinas rústicas e baratas.

A outra empresa tinha pequeno porte, atuava no Vale do Itajaí e exportava só para o Paraguai (menos de 3\% das vendas totais). Com poucos investimentos, não incorporara equipamento programável, nem introduzira $P \& D$ ou iniciara novas linhas de produtos. A proporção de engenheiros e técnicos era reduzida e declinante, e nada realizara em Q\&P ou em inovações organizacionais. Participava de associação empresarial local e desfrutava de boas relações de trabalho, mas não cooperava com outras firmas nem tinha vínculos institucionais importantes. A gestão era familiar e a postura, conservadora, tanto que não terceirizava e nunca diferenciara produto. A estratégia era de sobrevivência, vegetativa, em mercado com muitos concorrentes internos. A abertura comercial não afetava porque a empresa só fornecia para olarias semiartesanais, que dificilmente compram equipamentos sofisticados e caros.

3.2.3 Fabricantes de maquinário para beneficiamento de madeira

Somente um desses fabricantes não foi afetado pelas importações. Tratava-se de uma média empresa do Vale do Itajaí, fornecedora para fábricas de móveis e esquadrias, que exportava ( $10 \%$ das vendas) para países latino-americanos e para a Arábia Saudita e, embora com escassos investimentos, incorporara equipamento programável. Apresentava $\mathrm{P} \& \mathrm{D}$ e iniciativas em Q\&P desde os anos 80, tinha gerência profissional e estava implantando normas da ISO 9000, mas subcontratava pouco (geralmente atividades de menor valor) e não inovara a ponto de introduzir dispositivos microeletrônicos em seus produtos. Não usava insumos importados, porém conseguira parceria tecnológica e comercial com fabricantes europeus. A cooperação local era escassa, mas a firma usufruía de vínculos institucionais favoráveis, sobressaindo em mercado nacional de poucos concorrentes. Fora "poupada" da concorrência externa porque os produtos estrangeiros, embora de melhor qualidade, eram mais caros. Contudo, se as exigências tecnológicas do mercado aumentassem, as importações passariam a prejudicar. De todo modo, já priorizava a fabricação de máquinas maiores, com 
maior valor unitário e melhor design, aparecendo como empresa em reestruturação, com conduta estratégica que acenava com boas perspectivas.

Um pequeno fabricante joinvilense de máquinas simples, carente de ampla renovação no maquinário, foi atingido só ligeiramente pelas importações. Não apresentava equipamentos programáveis, $\mathrm{P} \& \mathrm{D}$, iniciativas em Q\&P ou inovações organizacionais, e a gestão era totalmente familiar. Sem exportar, e quase sem usar insumos importados, revelou interações locais limitadas: embora fizesse usinagem para terceiros, subcontratava muito pouco, e o envolvimento com associações empresariais e outras instituições era precário. A trajetória era vegetativa, de subsistência, sem registro de progresso técnico nos produtos durante as últimas décadas. Fora pouco afetado pelas importações porque atuava, com produtos robustos e baratos, em nicho de mercado pouco exigente, formado principalmente por serrarias. Todavia, as serrarias maiores já haviam adquirido maquinário importado, e isso preocupava, pois o diferencial de preço que favorecia a produção local não era tão grande.

A outra firma tinha pequeno porte, produzia no Vale do Itajaí e assinalou efeitos (pouco intensos) da abertura comercial. Exportava para Argentina e Chile ( $34 \%$ das vendas), mas, tendo investido pouco, não possuía equipamentos programáveis e necessitava modernizar $70 \%$ do equipamento. Tinha P\&D desde os anos 80 e introduzira novas linhas, com incorporação de dispositivos microeletrônicos aos produtos, porém nada fizera em Q\&P e em inovações organizacionais, apesar da gestão profissionalizada. Além de exportar bastante, usava insumos importados e tinha parcerias tecnológicas no exterior, mas suas relações locais eram limitadas, na subcontratação, na cooperação ou nos contatos institucionais. Assim caracterizada, inseria-se positivamente em mercado nacional de muitos concorrentes, mesmo após concordata na década de 80 e apesar do surgimento de restrições para extração de madeira que se refletiram nos clientes. A concorrência externa afetava só ligeiramente, porque os produtos importados eram sofisticados e caros para o mercado em que atuava.

\subsubsection{Fabricantes de máquinas especiais}

Só um pequeno produtor do Vale do Itajaí deplorou os efeitos da abertura comercial. Não exportava, pela baixa competitividade, mas investira razoavelmente, inclusive em tornos CNC. Possuía P\&D desde os anos 80 , e os engenheiros e técnicos, embora em queda, correspondiam a $18 \%$ dos funcionários. Por solicitação de clientes, introduzira linhas de produtos com dispositivos microeletrônicos que concentravam todo o faturamento. Nada realizara em Q\&P ou em inovações organizacionais, tendo conservado a gestão familiar. Parceria com firma sueca permitia a complementação do mix de produtos e facilitava o uso de insumos importados ( $5 \%$ do total), mas a subcontratação 
local era reduzida e os vínculos de cooperação e com instituições, inexistentes. A abertura comercial afetava porque seus preços não eram muito inferiores aos externos e porque não conseguia acompanhar as condições para compra dos concorrentes estrangeiros, embora levasse vantagem na prestação de serviço pós-venda. A firma decidiu se especializar, terceirizar no Brasil e no exterior e estabelecer parcerias internacionais visando à complementação de linhas e à atualização tecnológica.

Os outros dois fabricantes de máquinas especiais declararam-se não afetados pela abertura comercial.

Um deles, joinvilense de pequeno porte, investira pouco, mas, como se instalara recentemente, não precisava renovar o maquinário, mesmo sem contar com equipamento programável. Realizava $P \& D$ e seus engenheiros e técnicos representavam $39 \%$ do pessoal, mas nada fizera em Q\&P ou em inovações organizacionais. Incorporara linhas, com inovações de base microeletrônica nos produtos, que correspondiam à totalidade do faturamento, e usava insumos importados na proporção de $10 \%$. Embora sem exportar, tinha parceria com empresa italiana pela qual comprava controladores lógicos programáveis a preços menores. As condições locais eram favoráveis, tanto que aspectos como cooperação, relações institucionais, participação em associações empresariais, nível das relações de trabalho e do sistema de treinamento da mão-de-obra foram avaliados positivamente; terceirizava consideravelmente $(25 \%$ das atividades), incluindo a realização de projetos. Era firma de médio desempenho que, talvez pela criação recente, não possuía projetos definidos para o futuro. Frente às importações, o preço tinha importância primordial, e também a preferência dos clientes, pois os equipamentos importados requeriam ajustes e os fabricantes estrangeiros não asseguravam rapidez no atendimento.

A outra empresa exportava $20 \%$ das vendas para Argentina e (via empresa italiana) Albânia. Investira em melhoria da qualidade e, mesmo sem equipamento programável, declarou não carecer de renovação do maquinário. Tinha P\&D desde a década de 80 , e os engenheiros e técnicos, que dobraram em número, representavam $12 \%$ do pessoal. Não inovara em termos organizacionais, mas, sem interromper qualquer fabricação, incorporou linhas (sem inovação de base microeletrônica em produto) que representavam a maior parte do faturamento. Afora as exportações, quase nada efetuava em escala internacional, sendo insignificante o uso de insumos importados. Localmente, terceirizava na proporção de $10 \%$ do que produzia, e, apesar de escassos vínculos institucionais, participava de relações de cooperação. Era firma com desempenho regular, sem expansão, que subsistia à abertura comercial devido ao preço de seus produtos, menor que o dos importados em cerca de $20 \%$. 


\subsubsection{Fabricantes de maquinário para a indústria de alimentos}

Os dois fabricantes desse segmento, ambos de pequeno porte, não enfrentavam problemas com as importações. Um, de Jaraguá do Sul (região norte), exportava pouco (menos de $5 \%$ das vendas), porém tanto para países latino-americanos como para outros continentes. Devido à sua especialização, liderava no mercado nacional, até a frente de concorrentes maiores. Investira em aumento de capacidade e modernização, incorporando equipamento programável, e, com $\mathrm{P} \& \mathrm{D}$ desde os anos 80 , contratara mais engenheiros e técnicos. Sem mudanças organizacionais, avançara em Q\&P, revelando interesse na ISO 9000. Desativara a fabricação de máquinas semi-automatizadas, pela desatualização tecnológica e a orientação do mercado, e incorporara linhas (introduzindo controladores lógicos programáveis) que representavam todo o faturamento. Sem vínculos no exterior, utilizando poucos insumos importados e com subcontratação reduzida, assinalou, todavia, relações institucionais importantes. A "imunidade" perante as importações refletia particularidades como a fabricação de máquinas mais simples e adaptadas às necessidades dos clientes, de utilização relativamente mais vantajosa, ao que se acrescentava uma melhor prestação de assistência técnica pós-venda.

A outra firma, de Blumenau, tinha preços competitivos e tecnologia que permitiam exportar cerca de $14 \%$ das vendas, geralmente para países da América Latina. Desfrutando de certa autonomia tecnológica, pois desenvolvia modelos e produtos internamente, investira pouco nos anos 90 , já que o esforço maior ocorrera na instalação da fábrica, em 1986. Assim, embora sem equipamentos programáveis, necessitava pouca modernização de maquinário. A participação de engenheiros e técnicos permaneceu estável ( $9 \%$ do pessoal), mas a de profissionais em projetos e desenvolvimento de produto acusou incremento. As atividades de $P \& D$ sempre marcaram presença, porém as iniciativas em $\mathrm{Q} \& \mathrm{P}$ e as mudanças organizacionais eram recentes. A firma interrompera linhas, devido à perda de rentabilidade e às exigências do mercado, $\mathrm{e}$ incorporara outras, com dispositivos microeletrônicos em produtos, que respondiam pela totalidade do faturamento. Nesse processo, insumos importados foram incorporados e vínculos comerciais com parceiros no exterior, estabelecidos. A interação local merecia destaque: a firma cooperava e mantinha importantes relações institucionais, além de subcontratar cerca de $20 \%$ do que produzia. Era firma com boa trajetória gerencial, tecnológica e organizacional, coerente com a declarada presença entre os primeiros colocados no ranking dos concorrentes nacionais.

3.2.6 Fabricante de maquinário para fundições

Esse fabricante, joinvilense de pequeno porte, não se declarou afetado pelas importações. Investira pouco e necessitava renovar 30\% do maquinário; 
não tinha equipamento programável mas registrava $P \& D$ desde os anos 80 , com engenheiros e técnicos que, em número que dobrara, representavam $14 \%$ dos funcionários. As melhorias em Q\&P, ocorridas já nos anos 80 , revelavamse somente parciais, e nenhuma inovação organizacional fora efetuada, tendo a gestão permanecido familiar. As novas linhas respondiam pelo principal do faturamento, representando inovações em produto pela introdução de controladores lógicos programáveis. Embora não exportasse, desenvolveu parceria com firma suíça visando à incorporação de componentes e à melhoria tecnológica, pois os clientes exigiam máquinas com dispositivos microeletrônicos. Cooperava escassamente no local, e subcontratava menos de $5 \%$ do que produzia, mas usufruía de vínculos institucionais e relações de trabalho consideradas favoráveis. A "proteção" diante das importações resultava do preço e da importância dos serviços pós-venda: a ausência de exportações foi explicada, exatamente, pela necessidade de certas condições para a montagem dos produtos, o que fazia possíveis clientes no exterior preferirem equipamentos nacionais, com assistência técnica local, mais ágil. De qualquer maneira, tinha projeto para ampliar instalações e maquinário e, almejando importação de componentes e atualização tecnológica, intensificar as parcerias no exterior.

\subsubsection{Fabricante de maquinário para a indústria de fumo}

De médio porte e localizado em Blumenau, exportando $20 \%$ das vendas e liderando em mercado interno de escassa concorrência, esse fabricante informou não ter sido prejudicado pelas importações. Tinha tornos CNC e P\&D desde a década de 80 e investira razoavelmente nos anos 90 , quando contratou mais engenheiros e técnicos, correspondentes a $16 \%$ do quadro. Com gestão familiar, introduziu sistema de qualidade total e inovações organizacionais e iniciou a implantação de normas da ISO 9000. Incorporou linha de produtos com dispositivos microeletrônicos que representava $30 \%$ do faturamento, e subcontratava localmente $10 \%$ de suas atividades, em meio a vínculos (cooperação, relações institucionais, relações de trabalho) positivos. Era firma dinâmica e em expansão, com projeto de investimentos contemplando qualidade, novos métodos para programar a produção e compra de equipamentos para fabricar para o mercado de produtos automatizados. Era refratária ao aumento das importações, porque tinha preços competitivos, serviços pós-venda atraentes e produzia a pedido. Além disso, fabricava com tecnologia moderna, de padrão internacional, obtida mediante licenciamento de parceiro norte-americano.

3.2.8 Fabricante de maquinário para a indústria de pré moldados de concreto

De porte médio, localizado em Jaraguá do Sul, esse fabricante também não foi atingido pelas importações. Exportava pouco, mas tinha liderança em mercado nacional de escassos concorrentes. Investira em aumento de capacidade, 
principalmente em equipamento programável, e, com reflexos nas atividades de projeto e desenvolvimento de produto (e mesmo tendo P\&D desde os anos 80 ), dobrara o número de engenheiros e técnicos, que representavam $6 \%$ dos funcionários. Também recentes, e parciais, as iniciativas em Q\&P foram sustentadas por consultoria externa e protagonizadas junto com inovações organizacionais. A firma interrompeu linhas e incorporou outras, as quais, sem representar inovações de produto de base microeletrônica, respondiam pelo essencial do faturamento. No plano local, terceirizava as linhas de menor rentabilidade, mantinha vínculos de cooperação e institucionais diversos e usufruía de boas relações de trabalho. Era a empresa do painel com mais relações externas, envolvendo universidades, firmas (no Brasil e no exterior) e laboratórios tecnológicos. Vale assinalar que, se a aludida trajetória merece realce, a "imunidade" frente aos produtos importados estribava-se sobretudo na sofisticação destes: conforme a entrevista, os clientes preferiam os produtos da firma, mais simples e baratos. Mas havia outras vantagens: a empresa modernizara linhas em 1990 e encontrava-se repetindo o procedimento, inclusive em meio a parcerias na região e no exterior, como a que redundara em licença de fabricação obtida em uma firma norte-americana.

\section{Conclusão}

À primeira vista, as PMEs estudadas parecem sobreviventes da "depuração" representada pela abertura comercial. Entretanto, mais da metade não assinalou conseqüências negativas. Somente em alguns casos, a condição de sobrevivente se revelou, como nos dois fabricantes de maquinário para a indústria têxtil, que, mesmo reduzindo preço, sofriam com as importações porque produziam equipamentos tecnologicamente defasados. Num desses casos, a pressão associava-se também à penetração de máquinas de baixa qualidade e com preços relativamente menores. O caráter de sobrevivência chamou tanto mais atenção porque, apesar das adversidades, essas empresas não esboçaram qualquer estratégia clara de reação. Em contraste, uma outra firma do mesmo segmento evidenciou postura condizente: afetada pelo fato de não conseguir fazer frente às condições para compra oferecidas pelos fabricantes estrangeiros, tratou de buscar atualização tecnológica e melhoria na qualidade, inclusive mediante parcerias no exterior.

Muitas firmas prosseguiam em atividade por manterem presença em certos nichos de mercado. Nos segmentos de máquinas para a indústria têxtil, para a indústria cerâmica e para a indústria de beneficiamento de madeira, principalmente, a "imunidade" frente às importações (ou o pequeno efeito destas) resultava da fabricação de produtos comparativamente mais rústicos e 
baratos, dirigidos para mercados de escasso dinamismo. Algumas dessas firmas apresentavam condições absolutamente precárias, o que aponta para o seguinte aspecto da abertura comercial: empresas com trajetórias medíocres e comportamento vegetativo podem se revelar "protegidas"; outras, com inovações tecnológicas e organizacionais, ostentando condutas estratégicas, podem se achar vulnerabilizadas. O pequeno fabricante de equipamentos para a indústria cerâmica do Vale do Itajaí é exemplo do primeiro tipo; um dos médios fabricantes de máquinas para o setor cerâmico do Sul do Estado serve como ilustração do segundo.

Vantagens realmente genuínas frente às importações foram observadas nos dois fabricantes de maquinário para a indústria de alimentos, que se mantinham nos negócios e prosperavam devido a uma competitividade efetivamente "construída", com inovações tecnológicas e organizacionais, parcerias e outras iniciativas. $O$ mesmo comentário vale para os fabricantes de maquinário para a indústria de fumo e para a de pré-moldados de concreto. Inversamente, para cinco firmas que se declararam "protegidas", o substrato da posição era tão-somente o refúgio em nichos de mercado.

Em conjunto, os resultados indicam o caráter multiforme e complexo das relações envolvendo os níveis macro e microeconômico e sugerem o quanto as generalizações sobre os impactos das mudanças na economia podem levar a equívocos. Todavia, diante das alterações de marco regulatório, duas grandes orientações estariam a se mostrar como alternativas para as firmas: de um lado, o "salto para a frente", envolvendo inovações e reestruturação em geral; de outro, a busca da "proteção" representada pelos espaços de mercado com escassas exigências e reduzido dinamismo. As opções não se revelam desprovidas de conseqüências. A primeira, apesar de exigir um grande esforço inicial, pode frutificar positivamente já no curto prazo. A segunda tende a penalizar o comodismo com o risco, cada vez maior numa economia internacionalizada, de rápida eliminação do jogo competitivo. 


\section{Referências bibliográficas}

AUDRETSCH, D. B. Small business in industrial economics: the new learning. Revue d'Economie Industrielle, n. 67, 1er trim. 1994, p. 21-39.

BIELSCHOWSKY, R., STUMPO, G. A internacionalização da indústria brasileira: números e reflexões depois de alguns anos de abertura. In: BAUMANN, R. (org.). O Brasil e a economia global. Rio de Janeiro: Campus; SOBEET, 1996, p. 167-193.

DOSI, G. The nature of the innovative process. In: DOSI, G. et al. (eds.). Technical change and economic theory. London: Pinter Publishers, 1988, p. 221-238.

KATZ, J. M., STUMPO, G. La reestructuración industrial de Argentina, Brasil, Chile, Colombia y México en el curso de las dos ultimas décadas. In: KATZ, J. M. (ed.). Estabilización macroeconómica, reforma estructural y comportamiento industrial. Buenos Aires: CEPAL/IDRC - Alianza, 1996, p. 109-124.

LINS, H. N. Abertura comercial e competitividade de pequenos e médios fabricantes de bens de capital. XXV ENCONTRO NACIONAL DE ECONOMIA, 1997, Recife. Anais ...:ANPEC, 1997, v. 2, p. 662-681.

MIRANDA, J. C. Reestructuración industrial en un contexto de inestabilidad macroeconómica. El caso de Brasil. In: KATZ, J. M. (ed.). Estabilización macroeconómica, reforma estructural y comportamiento industrial. Buenos Aires: CEPAL/IDRC - Alianza, 1996, p. 163-190.

NELSON, R. R. Why do firms differ, and how does it matter?. Strategic Management Journal, v. 12, 1991, p. 61-74.

SENGENBERGER, W. Economic and social perspectives of small enterprises. Labour and Society, v. 13, n. 3, 1988, p. 249-259.

YOGUEL, G. Reestructuración económica, integración y PyMES: el caso de Brasil y Argentina. In: KATZ, Jorge M. (ed.). Estabilización macroeconómica, reforma estructural y comportamiento industrial. Buenos Aires: CEPAL/IDRC - Alianza, 1996, p. 577-625. 